\title{
Sexual Disorders in Women with Overactive Bladder and Urinary Stress Incontinence Compared to Controls: A Prospective Study
}

\section{Sexuelle Funktionsstörungen bei Frauen mit überaktiver Blase und Belastungsharninkontinenz im Vergleich mit einer Kontroll- gruppe: eine prospektive Studie}

(C) 98

Authors

Gert Naumann ${ }^{1,2}$, Thomas Hitschold ${ }^{3}$, Dominique Frohnmeyer ${ }^{4}$, Peter Majinge ${ }^{5}$, Rainer Lange ${ }^{3}$

Affiliations

1 Department of Obstetrics and Gynecology, Helios Klinikum Erfurt, Erfurt, Germany

2 University Women's Hospital, University Hospital Düsseldorf, Düsseldorf, Germany

3 Department of Obstetrics and Gynecology, Klinikum Worms, Worms, Germany

4 Department of Obstetrics and Gynecology, St Josefs Hospital, Wiesbaden, Germany

5 Urogynecology Unit, CCBRT Hospital, Dar es Salaam, Tanzania

Key words

overactive bladder, sexual disorder, coital incontinence, stress urinary incontinence, quality of life

\section{Schlüsselwörter}

überaktive Blase/Dranginkontinenz, sexuelle Störung, koitale Inkontinenz, stressbedingte Harninkontinenz, Lebensqualität

\section{received}

2.1. 2021

accepted after revision

4.5. 2021

Bibliography

Geburtsh Frauenheilk 2021; 81: 1039-1046

DOI 10.1055/a-1499-8392

ISSN 0016-5751

(C) 2021. The Author(s).

This is an open access article published by Thieme under the terms of the Creative Commons Attribution-NonDerivative-NonCommercial-License, permitting copying and reproduction so long as the original work is given appropriate credit. Contents may not be used for commercial purposes, or adapted, remixed, transformed or built upon. (https://creativecommons.org/licenses/by-nc-nd/4.0/)

Georg Thieme Verlag KG, Rüdigerstraße 14,

70469 Stuttgart, Germany

\author{
Correspondence \\ Priv.-Doz. Dr. med. habil. Gert Naumann \\ Department of Obstetrics and Gynecology, \\ Helios Klinikum Erfurt \\ Nordhäuser Straße 74, 99089 Erfurt, Germany \\ gert.naumann@helios-gesundheit.de
}

\section{ABSTRACT}

Introduction and Hypothesis Female urinary incontinence (UI) has a negative impact on sexual function and sexual quality of life (QoL) in women. But there is still no consensus on the type of UI or the prevalence of sexual dysfunction (SD). The aim of the study was to evaluate sexual disorders in women with overactive bladder (OAB) compared to patients with urinary stress incontinence (SUI) and healthy controls.

Materials and Methods 106 women presenting to a urogynecological outpatient clinic (referral clinic) were investigated using standardized questionnaires and the Female Sexual Function Index (FSFI-d). All 65 incontinent women underwent a full urodynamic examination; the controls (31) were non-incontinent women in the same age range who came for routine check-ups or minor disorders not involving micturition or pelvic floor function. Women with mixed urinary incontinence, a history of previous medical or surgical treatment for UI, recurrent urinary tract infections, previous radiation therapy or pelvic organ prolapse of more than stage 2 on the Pelvic Organ Prolapse Quantification (POP-Q) system were excluded.

Results 100 questionnaires could be evaluated (94.3\%). Thirty-four women had urinary stress incontinence, 35 had $\mathrm{OAB}, 31$ were controls. Mean age was 56 years, with no significant differences between groups. The scores of the questionnaire ranged from 2 to 35.1 points. The median score of OAB patients was significantly lower (17.6) than the median score of the controls $(26.5 ; p=0,004)$. The stress-incontinent women had a score of 21.95, which was lower than that of the controls but statistically non-significant $(p=0.051)$. In all subdomains, the OAB patients had lower scores than the stress-in- 
continent women and significantly lower values than the control group. Most striking was the impairment of "sexual interest in the last 4 weeks". The figure for "none or almost no sexual activity" was $80 \%$ for the OAB group, $64.7 \%$ for the group of stress-incontinent women and $48 \%$ for the control group. Incontinence during intercourse was reported by one $\mathrm{OAB}$ patient and 4 stress-incontinent women but did not occur in the control group.

Conclusions There is a high prevalence of SD in women with urinary incontinence. Patients with $\mathrm{OAB}$ reported a greater negative impact on sexual function and had significantly lower scores for the FSFI questionnaire than patients with stress incontinence or controls.

\section{ZUSAMMENFASSUNG}

Einleitung und Hypothese Die weibliche Harninkontinenz wirkt sich negativ auf die Sexualfunktion und die sexuelle Lebensqualität von betroffenen Frauen aus. Aber es herrscht immer noch kein Konsens über die Auswirkungen der Art der Harninkontinenz auf die Prävalenz von sexuellen Funktionsstörungen. Ziel dieser Studie war es, sexuelle Funktionsstörungen bei Frauen mit überaktiver Blase zu evaluieren im Vergleich zu Patientinnen mit Stressharninkontinenz sowie einer gesunden Kontrollgruppe.

Material und Methoden 106 Frauen, die an eine urogynäkologische Ambulanz überwiesen wurden, wurden mithilfe standardisierter Fragebögen und der deutschsprachigen Fassung des Female Sexual Function Index (FSFI-d) untersucht. Bei allen 65 inkontinenten Frauen wurde eine vollständige urodynamische Untersuchung durchgeführt, die Kontrollgruppe (31) bestand aus nicht inkontinenten Frauen desselben Alters, die sich wegen einer Routineuntersuchung oder kleineren Beschwerden, die nicht im Zusammenhang mit Harnentleerung oder Beckenbodenfunktion standen, vorstellig wurden. Frauen mit gemischter Harninkontinenz, medizi- nischen oder chirurgischen Inkontinenzbehandlungen in der Anamnese, wiederholten Harntraktinfekten, einer früheren Radiotherapie oder einem Beckenorganvorfall von mehr als Stadium II (bewertet mit dem [POP-Q] Beckenorgan-ProlapsQuantifizierungssystem) wurden nicht in die Studie aufgenommen.

Ergebnisse Es konnten insgesamt 100 Fragebogen evaluiert werden (94,3\%). 34 Frauen litten an Belastungsharninkontinenz, 35 hatte eine überaktive Blase/Dranginkontinenz, 31 Frauen dienten als Kontrollgruppe. Das mittlere Alter betrug 56 Jahre, und es gab keine signifikanten Unterschiede zwischen den Gruppen. Die erzielte Punktzahl für den Fragenbogen reichte von 2 bis 35,1 Punkten. Die Durchschnittswerte der Patientinnen mit überaktiver Blase waren signifikant niedriger $(17,6)$ als die durchschnittliche Punktzahl der Kontrollgruppe (26,5; $p=0,004)$. Die Punktzahl der Gruppe mit Belastungsharninkontinenz betrug 21,95, was auffällig war im Vergleich zur Kontrollgruppe. Trotzdem war dieser Unterschied nicht statistisch signifikant $(p=0,051)$. Patientinnen mit überaktiver Blase wiesen in allen Teilbereichen geringere Werte als Frauen mit Belastungsharninkontinenz und signifikant niedrigere Werte als die Kontrollgruppe auf. Am auffälligsten war die Beeinträchtigung von „sexuellem Interesse in den vergangenen 4 Wochen“: $80 \%$ der Patientinnen kreuzten „keine oder fast keine sexuelle Aktivitäten“ an, bei Frauen mit Belastungsharninkontinenz waren es $64,7 \%$ und bei der Kontrollgruppe $48 \%$. Eine Patientin mit überaktiver Blase und 4 der Frauen mit Belastungsharninkontinenz, aber keine der Frauen in der Kontrollgruppe vermeldeten Inkontinenz während des Geschlechtsverkehrs.

Schlussfolgerungen Obwohl es eine hohe Prävalenz an sexuellen Funktionsstörungen bei Frauen mit Harninkontinenz gab, wiesen Patientinnen mit überaktiver Blase eine stärkere negative Auswirkung auf die Sexualfunktion auf und hatten signifikant niedrigere Werte beim FSFI-Fragenbogen als Frauen mit Belastungsharninkontinenz oder Frauen aus der Kontrollgruppe.

\section{Brief Summary}

OAB patients had significantly lower scores for the FSFI questionnaire in general and in all subdomains compared to stress-incontinent women and controls.

\section{Introduction}

Many publications have reported impairments in the sexual life of women with urinary incontinence. Most of these publications are studies on sexual function after urinary stress incontinence operations [1,2]. The most common cause of preoperative sexual dysfunction is coital incontinence. More than $40 \%$ of women with urinary stress incontinence report that this interferes with their sexual function. The prevalence of coital incontinence is reported to be between 24-31\% [3]. It is important to distinguish between urinary loss during penetration and during orgasm. The former is mostly due to urinary stress incontinence [4], the latter is mostly associated with overactivity of the detrusor muscle [5].
Barber et al. reported that $22 \%$ of incontinent women had decreased sexual function and a reduction in libido caused by the fear of incontinence during intercourse or orgasm [6]. Sutherst and Brown found that $43 \%$ of women reported an adverse effect of incontinence on their sexual relations [7]. Other studies also report reduced lubrication and dyspareunia in incontinent women [8]. Women with sexual complaints report more pelvic floor disorders [9].

Rogers et al. reported libido reduction, arousal problems, disturbance of orgasm and dyspareunia in $46 \%$ of incontinent patients [10]. Korda and colleagues interviewed 4000 women between the ages of 19 and 82 about the impact of urinary incontinence on their sexual life. $46.5 \%$ of the incontinent women below the age of 50 reported decreased sexual arousal. This difference was not seen in older women (> 50 years old) [9].

A recent study by Gomes et al. showed a high prevalence of SD in women with urinary incontinence, irrespective of the type of UI. The greater the severity of UI, the worse the FSFI sexuality questionnaire scores [11]. 
- Table 1 FSFI domain scores and full-scale score [17].

\begin{tabular}{|c|c|c|c|c|c|}
\hline Domain & Questions & Score range & Factor & Minimum score & Maximum score \\
\hline Sexual interest & 1,2 & $1-5$ & 0.6 & 1.2 & 6.0 \\
\hline Arousal & $3,4,5,6$ & $0-5$ & 0.3 & 0 & 6.0 \\
\hline Lubrication & $7,8,9,10$ & $0-5$ & 0.3 & 0 & 6.0 \\
\hline Orgasm & $11,12,13$ & $0-5$ & 0.4 & 0 & 6.0 \\
\hline Satisfaction & $14,15,16$ & 0 (or 1$)-5$ & 0.4 & 0.8 & 6.0 \\
\hline \multirow[t]{2}{*}{ Pain } & $17,18,19$ & $0-5$ & 0.4 & 0 & 6.0 \\
\hline & \multicolumn{2}{|c|}{ Full-scale score range } & & 2.0 & 36 \\
\hline
\end{tabular}

There are only a few reports about a correlation between $O A B$ and sexual function. Asoglu et al. reported more anxiety disorders and a reduced quality of life in women with $O A B$ compared to women with urinary stress incontinence [12]. A Norwegian study by Bo et al. found that women with mixed incontinence reported greater levels of sexual dysfunction than those with stress incontinence alone [13]. Coyne et al. investigated 43 women with $O A B$, the majority of whom were incontinent OAB-patients $(n=23)$, who reported a reduction in their sexual interest. All of them reported a negative impact on their sexual life and difficulties in reaching orgasm [14].

The aim of our study was to investigate the prevalence of sexual dysfunction in women with $O A B$ and urinary stress incontinence in patients presenting to the urogynecological outpatient clinic of our pelvic floor center. which has a high incidence of patients with sexual disorders due to OAB.

\section{Materials and Methods}

\section{Study cohort}

In this prospective cohort study, patients presenting to our outpatient clinic between 2016 and 2018 for urogynecological examination were enrolled in the study. A total of 106 women were included in the study and were divided into the following groups: stress incontinence alone $(n=34)$, overactive bladder alone $(n=35)$ and continent women presenting for routine check-ups or minor non-urogynecological disorders as the controls $(n=31)$. Six refused to complete the questionnaire. We enrolled sequential patients in the $O A B$ group. As these patients were the rarest, other patients were included based on the number of included $O A B$ patients to prevent a time shift.

Exclusion criteria were: prolapse (> stage 1 ) or previous pelvic floor operations or incomplete clinical examination. Patients with $\mathrm{OAB}$ and SUI who had not had prior medical therapy for urinary incontinence were included. Psychiatric patients and patients with severe diseases which could impede sexual function were excluded. Women with chronic pelvic pain and those who reported pelvic pain during examination were also excluded from the study.
All incontinent women underwent a full urodynamic examination [15] with

- urogynecological history including

- micturition symptoms

- micturition chart

- sexual history

- bowel symptoms

- gynecological status including POPQ

- hormonal status based on vaginal smear

- urodynamic examination (urethrocystometry with stress test in supine and standing positions)

- 3-/4-D pelvic floor sonography

The information was recorded using a standardized, non-validated log and included a micturition log of at least 48 hours.

Stress incontinence was defined as the loss of urine in the absence of a detrusor contraction without any symptom of overactive bladder. Overactive bladder was diagnosed based on the ICS definition: urgency and/or frequency in the absence of any other detectable bladder disease. All patients with overactive bladder included in this study suffered from incontinence (incontinent $\mathrm{OAB})$. Patients with mixed incontinence, including those with a previous history of stress incontinence surgery or medical treatment for incontinence within the last six months, were excluded.

\section{Questionnaire analysis}

Sexual history was recorded using the validated German-language "Female Sexual Function Index" (FSFI-d) questionnaire following informed consent. The questionnaire, developed by Rosen [16], was validated in German by Berner [17] and is the sole questionnaire in German which assesses female sexual function. It records the last four weeks of sexual activity for the domains: libido, sexual arousal, lubrication, orgasm, emotional satisfaction, and painful sensations. Each question has 5 possible answers rated with a maximum of 5 points which are linked to a special factor ranking for the different domains. Each of the six domains studied can be validated with a maximum score of six. A total score of between 0 and 36 is possible ( $\bullet$ Table $\mathbf{1}$ ).

Individual domain scores and full-scale FSFI scores were obtained using a computational formula. Individual domain scores were obtained by adding the scores of individual items compris- 
- Table 2 Mean scores for sexual function domains of the FSFI according to UI type for 100 women included in the study.

\begin{tabular}{|c|c|c|c|c|}
\hline Domain & $\begin{array}{l}\text { OAB } \\
\mathrm{n}=35 \\
\text { Median [IQR] }\end{array}$ & $\begin{array}{l}\text { SUI } \\
\mathrm{n}=34 \\
\text { Median [IQR] }\end{array}$ & $\begin{array}{l}\text { Control } \\
\mathrm{n}=31 \\
\text { Median [IQR] }\end{array}$ & p value \\
\hline Total score & $17.6[4,8 ; 27.3]$ & $22.0[5.7 ; 29.0]$ & $26.5[21.8 ; 30.5]$ & 0.010 \\
\hline Sexual interest & $2.3[1.2 ; 3.0]$ & $3.2[2.3 ; 3.6]$ & $3.4[2.8 ; 3.6]$ & 0.024 \\
\hline Arousal & $2.7[0.3 ; 3.9]$ & $3.2[1.0 ; 4.6]$ & $3.9[2.7 ; 4.8]$ & 0.030 \\
\hline Lubrication & $3.3[0.0 ; 5.4]$ & $3.8[0.0 ; 5.8]$ & $4.8[3.9 ; 6.0]$ & 0.046 \\
\hline Orgasm & $2.8[0.0 ; 4.8]$ & $3.8[0.0 ; 5.3]$ & $4.8[3.6 ; 5.6]$ & 0.014 \\
\hline Satisfaction & $3.6[2.4 ; 4.8]$ & $3.8[2.4 ; 5.2]$ & $4.8[3.2 ; 5.6]$ & 0.046 \\
\hline Pain & $3.2[0.0 ; 6.0]$ & $3.8[0.0 ; 6.0]$ & $6.0[4.8 ; 6.0]$ & 0.010 \\
\hline
\end{tabular}

ing the domain and multiplying the sum by the domain factor. The full-scale score was obtained by adding the six domain scores. The score correlates positively with sexual function.

The FSFI-d allows us to discriminate between "sexual dysfunction" and "no sexual dysfunction", with a threshold value of 26.55 considered optimal [18].

In 2000, Rosen et al. published a study of healthy women with a score of $30.5 \pm 5.29$ [16]. Communal et al. defined sexual function as "good" when the score was 30-36, "moderate" when it was 23-29 and "weak" when the score was below 23 [19].

Written consent was obtained from all patients who agreed to participate in the study. All patients signed a consent form.

\section{Statistical methods}

Statistical analysis was performed using the SPSS program, version 23.

We did not formally calculate a sample size because we had no pilot study for the groups to create data for a sample size calculation before this study. However, we estimated that recruiting 30 patients per group would provide enough preliminary data to reach a statistical power of $80 \%$ for the study, based on other studies comparing female sexual function in cases with different types of urinary incontinence [33].

Differences between the three groups were calculated with Mann-Whitney U-test. The results of explorative statistics were calculated with a significance of $5 \%(p \leq 0.05)$. Kruskal-Wallis test was used to compare sexual function domains and subtypes of $\mathrm{UI}$ and controls.

\section{Results}

The overall median age was 57.5 years (IQR 40.0; 64.75). Median age in the OAB group was $60.0(25-75)$ years; in the SUl group it was 57.5 (30-76) years, and in the control group it was 54.0 (2977 ) years (Kruskal-Wallis test: $p=0.397)$. There were no statistical differences between the different groups.

\section{Total FSFI score}

Overall, questionnaire scores ranged between 2 and 35.1 points (maximum: 36). The median score was 22.4. Women with OAB had a median score of 17.6, those with SUI had a median score of 22.0 and the control group had a score of 26.5 ( $\triangleright$ Table 2 ).

Variance analysis calculated with the Kruskal-Wallis test showed a highly significant difference of 0.01 between the total scores of the three groups. Mann-Whitney U-test showed no significant difference between the two groups with incontinence (OAB, SUI) $(p=0.275)$ but a noticeable difference of 4.55 points between stress-incontinent women and controls, although the difference was not statistically significant $(p=0.051)$. However, the difference between $\mathrm{OAB}$ patients and controls was highly significant $(p=0.004)$.

\section{Categories/FSFI subgroups}

Sexual interest

The subgroup "sexual interest" has two questions:

1. Over the past 4 weeks, how often did you feel sexual desire or interest?

2. Over the past 4 weeks, how would you rate your level (degree) of sexual desire or interest?

We found the OAB group had the lowest scores with 2.3, while stress-incontinent women scored 3.2 and controls scored 3.4. Mann-Whitney U-test showed no difference between controls and women with stress incontinence but a significant difference $(p=0.046)$ between $O A B$ patients and stress-incontinent women and a highly significant difference between $O A B$ patients and controls $(p=0.001)$.

\section{Sexual arousal}

Questions 3 to 6 of the FSFI-d concerned sexual arousal. Scores ranged from 0 to a maximum of 6.0 points.

Here again, the lowest median was found for the group of $O A B$ patients (2.7), while the group of women with stress incontinence had a median of 3.2 and the control group had the highest score with 3.9; the differences were significant. 
Mann-Whitney U-test showed a significant difference between the $O A B$ group and the control group $(p=0.048)$ but not between the other groups $(\mathrm{OAB} /$ stress incontinence $p=0.522$; stress incontinence/controls $\mathrm{p}=0.212$ ).

\section{Lubrication}

Questions 7-10 were on lubrication. The overall score in this subgroup ranged from 0.0 to 6.0 . The highest score was for the control group (median value 4.8), while stress-incontinent women had a median value of 3.8 and women with $O A B$ only had a score of 3.3. There was a significant difference between the $O A B$ group and the control group $(p=0.018)$ but not between OAB/stress incontinence $(p=0.503)$ or stress incontinence/controls $(p=0.116)$.

\section{Orgasm}

Questions 11 to 13 of the FSFI focused on orgasm. The overall score was the same as that for the subgroups "lubrication" and "arousal". The OAB group had a median score of 2.8 , patients with stress incontinence scored 3.8, and controls scored 4.8. There was a highly significant difference between the $O A B$ group and controls ( $p=0.006$ ) but not between the stress-incontinent women and controls $(p=0.062)$ and between incontinent groups $(p=0.402)$.

\section{Satisfaction}

This area was covered by questions $14-16$, with scores ranging from 0.8 to 6.0. Satisfaction had higher scores compared to other domains (OAB 3.6; SUI 3.8; controls 4.8). The difference between the $O A B$ group and the control group was highly significant $(p=0.014)$ but comparisons between other groups were not.

\section{Pain}

Questions 17-19 focused on pain during intercourse, with the same scores are reported above. Here, the difference between the $O A B$ group and controls $(p=0.008)$ was highly significant and the difference between stress-incontinent women and controls $(p=0.01)$ was also significant but not the difference between women with $\mathrm{OAB}$ and women with stress incontinence $(p=0.828)$.

We found significant differences between the OAB group and the control group in the FSFI-d scores for sexual function in all subgroups of this domain. This was most evident for the category "sexual interest" $(p=0.001)$ ( $\triangleright$ Table 2$)$.

There was also a significant difference between OAB patients and the stress-incontinence group in this subgroup. Patients with urinary stress incontinence only differed significantly from controls in the domain "pain" $(p=0.01)$.

\section{Particular questions in the FSFI}

$80 \%$ of women with $\mathrm{OAB}$ responded to Question 1: "Over the past 4 weeks, how often did you feel sexual desire or interest?" with "A few times (less than half the time)" or "Almost never or never". $64.7 \%$ of respondents in the group with stress incontinence and $48.4 \%$ of patients in the control group also gave these answers.

In response to Question 2: "Over the past four weeks, how would you rate your level (degree) of sexual interest?", 74\% of the OAB group answered "low" or "very low or none at all", $17.1 \%$ replied "moderate" and only $8.6 \%$ answered "high", but none of them answered "very high". Patients with stress incontinence rated their sexual desire higher: almost half of them answered "low" or "very low or none at all", 41.2\% answered "moderate", and $8.8 \%$ "high" or "very high".

One of the 21 sexually active patients with $O A B$ and 4 of 22 patients with SUI reported involuntary loss of urine during intercourse (controls $n=0 / 28$ ).

\section{Discussion}

Patients with pelvic floor disorders show reduced sexual wellbeing. The median age in our study was 57.7 years, demonstrating the late onset of a diagnosis of incontinence in the higher age groups, although younger women also suffer from this complaint. The age distribution was similar in all three groups.

Due to the higher mean age, the level of sexual disorder was higher; only 37 out of 100 participants achieved a total score of more than 26.55, which is the level of normal sexual function [18]. Women in all of the groups were matched according to age.

\section{Assessment of the questionnaires}

Contradictory or divergent results were seen when evaluating the different questions. One possible answer to Questions 3 to 14 and 17 to 19 was "no sexual activity". But this answer was not often given in response to these particular questions. In the control group, this possible answer was given in 12.9 to $16.1 \%$ of cases; it was given in 26.5-32.4\% of cases in the group with urinary stress incontinence, and in $20.0-40.0 \%$ of cases in the group of $\mathrm{OAB}$ patients. Although the questionnaire was suitable for women without sexual activity (due to the lack of a partner), some questions were confusing for a number of patients and some forms were therefore answered inaccurately.

Very often the answer to Question 15 "Over the past 4 weeks, how satisfied have you been with your sexual relationship with your partner?" was not completed, mostly in cases when women did not have a partner, because there was no possible answer apart from "no sexual activity". We added this question when interviewing the patient.

Many studies $[1-3,20]$ have shown the impact of urinary stress incontinence on sexual function. Our results also show an impact but found no significant difference between continent women and those with urinary stress incontinence. Only a few studies have reported a correlation between $O A B$ and sexual dysfunction [21-24]. In our study, we found that women with OAB are significantly more likely to have sexual dysfunction than continent women, based on the total scores for the questionnaire $(p=0.004)$. Women with urinary stress incontinence had lower scores than healthy subjects, but this difference was not significant $(p=0.051)$.

In the analysis of all subgroups, patients with $O A B$ reported a significant negative impact compared to controls, while comparisons of the SUI group with control patients and of the OAB/SUI groups did show any significant differences. The results of this study support the higher negative impact of $O A B$ on sexual life. 
Wiegel et al. [18] determined the threshold value of the FSFI-d questionnaire to be 26.55 points as an indication of some degree of sexual dysfunction. Based on this, in our study $71.4 \%$ of the OAB group, $67.6 \%$ of the urinary stress-incontinent patients, and $48.4 \%$ of controls showed some sexual dysfunction. This seems to be very high in our opinion. Communal et al. [19] defined less than 23 points as dysfunctional. In this case, $62.9 \%$ of the $O A B$ group, $58.8 \%$ of the urinary stress-incontinent patients, and $35.5 \%$ of the controls had sexual dysfunction.

As regards the different domains of the questionnaire (sexual interest, arousal, lubrication, orgasm, satisfaction) we found a significant difference between $O A B$ and controls for all of the domains.

Our study showed statistical differences in sexual interest between $\mathrm{OAB}$ and controls and $\mathrm{OAB} / \mathrm{SU}$ l patients. These findings correlate with those of other studies: Coyne et al. [14] reported reduced sexual interest in half of OAB-patients. Gordon et al. [20] noted sexual dysfunction in $71 \%$ of OAB-patients. Coyne reported reduced sexual interest in more than half of incontinent patients and a negative impact of $O A B$ on the sexual life of these patients, including difficulties in reaching orgasm [14]. The reduction of sexual interest was particularly noticeable in our study. $80 \%$ of our patients with $O A B$ answered the question about the frequency of sexual interest with "sometimes (about half the time)", "a few times (less than half the time)" or even "almost never or never". $64.7 \%$ of the group of stress-incontinent women and $48.4 \%$ of the control group gave the same response. The degree of sexual interest question was also answered with "low" or "very low or none at all" by $74.4 \%$ of OAB-patients.

A similar picture was also seen for the category "arousal”, with the $\mathrm{OAB}$ group showing significantly lower values and a median of 2.70 compared to controls which had a median of 3.90 $(p=0.048)$. The control group had better results than the group of women with urinary stress incontinence, but the difference between the two groups was not significant.

Disturbances of orgasm in women with incontinence has been reported in several studies $[3,25,26]$. We found a significant difference between the $O A B$ group and the healthy group $(p=0.006)$, but no significant difference between stress-incontinent and continent women ( $p=0.062)$.

Handa et al. [8] reported a reduction of libido in women with incontinence as well as reduced lubrication and increased dyspareunia. We also found a significant difference between the OAB group and controls $(p=0.018)$, but no statistically significant difference between the other two groups. Our results were similar to the findings of Handa et al. in terms of pain during intercourse and dyspareunia. In our study, there was a significant difference between controls and women with urinary stress incontinence but almost no difference between $\mathrm{OAB}$ women and stress-incontinent women $(p=0.828)$. What was notable was that the difference between stress-incontinent women and controls for the subgroup "pain" was significant, but the difference for the total score and other domains was not. This could be explained by anatomical changes in these women.

There was also a significant difference between OAB-patients and continent women $(p=0.0149)$ but not between the other groups for the domain "satisfaction". The low scores of patients with $\mathrm{OAB}$ can be explained by the high prevalence of sexual inactivity in this group.

\section{Sexual inactivity}

$34 \%$ of OAB patients and $29 \%$ of the stress-incontinent group but only $14 \%$ of the continent women reported being sexually inactive. One of the weaknesses of this questionnaire is the lack of differentiation between cohabitation with a partner and masturbation without a partner. Sometimes older women were not able to answer all of the questions accurately.

\section{Incontinence during intercourse}

While other studies have reported a loss of urine during intercourse in $24-35 \%[20,27]$, only $15 \%$ of stress-incontinent patients, one patient with $\mathrm{OAB}$ and none of the continent women reported this symptom in our study.

Barber et al. [4] differentiated between loss of urine during penetration and incontinence during orgasm. Our questionnaire did not differentiate between the two.

\section{Arousal, lubrication, orgasm, and satisfaction}

$40 \%$ of the $O A B$ patients reported achieving orgasm without or only with little difficulty, as did $47 \%$ of women with urinary stress incontinence and $67 \%$ of the continent women. $25 \%$ of the OAB group said they found it impossible or very difficult to achieve orgasm. But this figure was very similar across all the groups: $23.5 \%$ of the stress-incontinent group and $19.3 \%$ of the continent women reported the same problem.

"Discomfort and pain" was the only subgroup where the values of $\mathrm{OAB}$ patients were better than those of the stress-incontinent women ( $18 \%$ versus $12 \%$ in OAB patients); only $3 \%$ of healthy women reported discomfort and pain. One reason for this could be anatomical changes in women with pelvic floor weakness.

It is not clear whether OAB impairs sexual life or vice versa, or if there is a common cause. The FSFI-d questionnaire only asks about the last four weeks of sexual activity, so we have no definite knowledge about the period of incontinence or about the disturbance of sexual function. In our experience, women who are sexually inactive in their partnership report this some years before the onset of $\mathrm{OAB}$. But this should be clarified by further studies.

Studies report an impact of OAB symptoms on sexual function and that $O A B$ itself is often correlated with psychosomatic disease $[5,20,28]$. Women with OAB suffer more often from depression and anxiety disorders than those with urinary stress incontinence [28-30].

A recent study has shown that after one year, about $18 \%$ of women with urinary stress incontinence develop combined stress/urge incontinence [31]. MRI studies have shown that women with $O A B$ show activity in other brain regions in relation to urinary urgency than healthy controls, indicating a recruitment of alternative pathways when loss of bladder control is feared. In fact, we all train our brain to control two reflexes which are not under the control of our senses, i.e., micturition and defecation [32]. The regulation of sexual reflexes occurs later in life and possibly follows similar pathways to those of micturition, targeting the same organ system. This could explain the fact that disorders in both systems are significantly often found together. It would be 
of interest to see whether our clinical observation that disturbances of sexual function appear years before $O A B$ symptoms can be verified, as this hypothesis could offer a new approach for the therapy of OAB and of sexual disorders.

\section{Conclusion}

$\mathrm{OAB}$ and stress urinary incontinence have a significant negative impact on sexual life.

There is a high prevalence of SD in women with urinary incontinence, irrespective of the type of UI. A higher degree of incontinence is related to lower FSFI scores.

When all FSFI domains were analyzed, patients with OAB had significant sexual dysfunction compared to controls. Comparisons between SUI and control patients and OAB/SUI did not show significant differences with the exception of sexual interest. The results of this study support a higher negative impact of $O A B$ on sexual life. There are more differences between $O A B$ patients and controls than between SUI patients and controls.

Further studies should focus more on the impact of $O A B$ on sexual function.

\section{Authors Contributions}

Naumann: Project development, data collection, management data analysis, manuscript writing/editing.

Hitschold: Project development, management data analysis.

Frohnmeyer: Data collection, management data analysis.

Majinge: Project development, manuscript writing/editing.

Lange: Project development, data collection, management data analysis, manuscript writing/editing.

\section{Conflict of Interest}

Naumann: Promedon (research, travel expenses).

Frohnmayer, Majinge, Hitschold: The authors declare that they have no conflicts of interest.

Lange: coma urogyn GmbH (co-owner), contura (advisory board),

Coloplast (travel expenses, speaker, research).

\section{References}

[1] Glavind K, Larsen T, Lindquist AS. Sexual function in women before and after tension-free vaginal tape operation for stress urinary incontinence. Acta Obstet Gynecol Scand 2014; 93: 986-990

[2] Naumann G, Steetskamp J, Laterza R et al. Sexual function and quality of life following retropubic TVT and single-incision sling in women with stress urinary incontinence: results of a prospective study. Arch Gynecol Obstet 2013; 287: 959-966

[3] Aslan G, Köseoğlu H, Sadik O et al. Sexual function in women with urinary incontinence. Int J Impot Res 2005; 17: 248-251

[4] Barber MD, Dowsett SA, Mullen KJ et al. The impact of stress urinary incontinence on sexual activity in women. Cleve Clin J Med 2005; 2: 225232

[5] Cartwright R, Elvy S, Cardozo L. Do women with female ejaculation have detrusor overactivity? J Sex Med 2007; 4: 1655-1658
[6] Barber MD, Visco AG, Wyman JF et al. Continence Program for Women Research Group Sexual function in women with urinary incontinence and pelvic organ prolapse. Obstet Gynecol 2002; 99: 281-289

[7] Sutherst J, Brown M. Sexual dysfunction associated with urinary incontinence. Urol Int 1980; 35: 414-416

[8] Handa VL, Harvey L, Cundiff GW et al. Sexual function among women with urinary incontinence and pelvic organ prolapse. Am J Obstet Gynecol 2004; 191: 751-756

[9] Korda JB, Braun M, Engelmann UH. [Sexual dysfunction at urinary incontinence]. Urologe A 2007; 46: 1058-1065

[10] Rogers GR, Villareal A, Kammerer-Doak D et al. Sexual function in women with and without urinary incontinence and/or pelvic organ prolapse. Int Urogynecol J 2001; 12: 361-365

[11] Gomes TA, Faber MA, Botta B et al. Severity of urinary incontinence is associated with prevalence of sexual dysfunction. Int Urogynecol J 2020; 31: 1669-1674

[12] Asoglu MR, Selcuk S, Cam C et al. Effects of urinary incontinence subtypes on women's quality of life (including sexual life) and psychosocial state. Eur J Obstet Gynecol Reprod Biol 2014; 176: 187-190

[13] Bo K, Talseth T, Vinsnes A. Randomized controlled trial on the effect of pelvic floor muscle training on quality of life and sexual problems in genuine stress incontinent women. Acta Obstet Gynecol Scand 2000; 79: 598-603

[14] Coyne KS, Margolis MK, Jumadilova Z et al. Overactive bladder and women's sexual health: what is the impact? J Sex Med 2007; 4: 656-666

[15] Nambiar AK, Bosch R, Cruz F et al. EAU Guidelines on Assessment and Nonsurgical Management of Urinary Incontinence. Eur Urol 2018; 73 : 596-609

[16] Rosen R, Brown C, Heiman J et al. The Female Sexual Function Index (FSFI): a multidimensional self-report instrument for the assessment of female sexual function. J Sex Marital Ther 2000; 26: 191-208

[17] Berner MM, Zahradnik L, Haerter HP et al. Überprüfung der Gültigkeit und Zuverlässigkeit des deutschen Female Sexual Function Index (FSFI-d). Geburtshilfe Frauenheilkd 2004; 64: 293-303

[18] Wiegel M, Meston C, Rosen R. The female sexual function index (FSFI): cross-validation and development of clinical cutoff scores. J Sex Marital Ther 2005; 31: 1-20

[19] Communal PH, Chevret-Measson M, Golfier F et al. Sexuality after sigmoid colpopoiesis in patients with Mayer-Rokitansky-Kuster-Hauser Syndrome. Fertil Steril 2003; 80: 600-606

[20] Gordon D, Groutz A, Sinai T et al. Sexual function in women attending a urogynecology clinic. Int Urogynecol J 1999; 10: 325-328

[21] Hakimi S, Aminian E, Alizadeh SM et al. Risk factors of overactive bladder syndrome and its relation to sexual function in menopausal women. Urologia 2018; 85: 10-14

[22] Juliato CRT, Melotti IGR, Junior LCS et al. Does the Severity of Overactive Bladder Symptoms Correlate With Risk for Female Sexual Dysfunction? J Sex Med 2017; 14: 904-909

[23] Ergenoglu AM, Yeniel AÖ, Itil IM et al. Overactive bladder and its effects on sexual dysfunction among women. Acta Obstet Gynecol Scand 2013; 92: 1202-1207

[24] Lai HH, Shen B, Rawal A et al. The Relationship Between Anxiety and Overactive Bladder or Urinary Incontinence Symptoms in the Clinical Population. Urology 2016; 98: 50-57

[25] Dennerstein L, Koochaki P, Barton I et al. Hypoactive sexual desire disorder in postmenopausal women: A survey of Western European women. J Sex Med 2006; 3: 212-222

[26] Melville JL, Delaney K, Newton K et al. Incontinence severity and major depression in incontinent women. Obstet Gynecol 2005; 106: 585-592

[27] Duralde ER, Rowen TS. Urinary Incontinence and Associated Female Sexual dysfunction. Sex Med Rev 2017; 5: 470-485 
[28] Zorn BH, Montgomery $\mathrm{H}$, Pieper $\mathrm{K}$ et al. Urinary incontinence and depression. J Urol 1999; 162: 82-84

[29] Macaulay AJ, Stern RS, Holmes DM et al. Micturition and the mind: psychological factors in the aetiology and treatment of urinary symptoms in women. Br Med J (Clin Res Ed) 1987; 294: 540-543

[30] Abrams P, Cardozo L, Fall M et al. The standardisation of terminology in lower urinary tract function: report from the standardisation sub-committee of the International Continence Society. Urology 2003; 61: 37-49
[31] Minassian VA, Yan X, Pilzek AL et al. Does transition of urinary incontinence from one subtype to another represent progression of the disease? Int Urogynecol J 2018; 29: 1179-1185

[32] Griffiths D, Tadic SD, Schaefer W et al. Cerebral control of the bladder in normal and urge-incontinent women. Neuroimage 2007; 37: 1-7

[33] Zahariou A, Karamouti M, Tyligada E et al. Sexual function in women with overactive bladder. Female Pelvic Med Reconstr Surg 2010; 16: 31-36 